\title{
Fatigue Fracture of a Compressor Blade of an Aeroengine: What Caused this Failure?
}

\author{
M. Sujata $\cdot$ S. K. Bhaumik
}

Submitted: 2 February 2015/in revised form: 21 March 2015/Published online: 24 April 2015

(c) ASM International 2015

\begin{abstract}
The success of failure analysis depends on the use of appropriate analytical techniques in proper sequence. The approach and the methodology to be adopted for a particular failure investigation largely depend on the nature of failure. Collection of background information leading to development of a complete case history of the failure is, therefore, essential. This is followed by examination of the components, to establish the physical cause of failure, mostly through metallurgical investigation and evaluation of the material of construction. Metallurgical investigation can pinpoint the physical cause of failure but often falls short of identifying the true cause of failure. It has been seen that many a time, the true cause of failure is not established due to overlooking of minor details and not because of lack of advanced knowledge. This aspect of failure analysis has been highlighted in this article through a practical example. The failure involved fatigue fracture of a high pressure compressor blade of an aeroengine. The failure occurred within $12.2 \mathrm{~h}$ of engine run on the test bed.
\end{abstract}

Keywords Failure analysis - Background information Physical cause of failure - True cause of failure

\section{Introduction}

There are compelling reasons for investigating engineering failures. Unless the true cause of the failure is established,

M. Sujata · S. K. Bhaumik $(\bowtie)$

National Aerospace Laboratories, Materials Science Division,

Council of Scientific and Industrial Research (CSIR),

Bangalore 560 017, India

e-mail: subir@nal.res.in no remedial action can be initiated. The lessons learned from failure analysis are vital for the engineering profession and the industries that aim at design and manufacture of products with minimum probability of the service failure [1].

The first and foremost task in conducting a successful failure investigation is to develop a complete case history of the failure [2]. This requires information about the failed component/system and the failure itself. In case of failure in complex engineering systems, collecting information before proceeding with the investigation becomes a formidable and challenging task. If the information is incorrect or concealed or overlooked, the investigation may take a wrong direction resulting in not only wasteful work but also loss of important evidences. Many a time, the failure analysts do not have access to all information that the manufacturer or the user may have. This poses difficulties to the investigators in deciding the approach to be followed and draw a detailed test plan for a particular failure case. It is, however, the job of the failure analyst to make attempts in obtaining relevant information about the failure as and when required throughout the investigation process. It is known that the same physical failure can occur due to several different reasons, and hence identification of cause of failure for the case at hand is important [3].

The goal of failure analysis is to determine what caused the failure. Metallurgical investigation can reveal the physical cause but may not always lead to determination of the true cause of failure. This is because in most cases, failure occurs as a culmination of many events or factors [4]. Sometimes, with the information available, it is impossible to determine the primary factor that was responsible for the failure to occur.

In this article, failure investigation of a high pressure compressor blade (HPCR) of an aero-engine has been 
discussed. Despite exhaustive metallurgical investigation and consideration of all available information, the true cause of failure could not be established. Yet, circumstances demanded that a conclusion be formulated based on educated speculation and opinion. However, while compiling data for recommending rejection of the entire batch of the blades, certain information was fortuitously revealed. Probing this information further, the primary cause of the failure of the blade could be identified.

\section{The Failure}

There was an incident of HPCR blade failure in an aeroengine during the run on the engine test bed. It was reported that engine surge occurred during maximum reheat run with $103 \%$ RPM of the high pressure spool. Strip examination of the engine revealed that one of the 1st stage HPCR blades had fractured in the airfoil close to the blade root platform (Fig. 1). This had resulted in severe damage to the engine. At the time of incidence, the engine had logged in a total of $12.2 \mathrm{~h}$. The fractured blade was submitted to the laboratory for investigation and establishment of the probable cause(s) of failure (Fig. 2). The HPCR blades were made of BT-6 Ti-alloy of nominal composition as given in Table 1.

\section{Metallurgical Investigation}

\section{Visual and Stereo-Binocular Examination}

The HPCR blade had fractured in the airfoil at a height of about $6 \mathrm{~mm}$ from the blade root platform. The fracture surface showed presence of a half-moon-shaped region with well-defined beach marks or crack arrest marks, typical of progressive mode of crack propagation. Tracing back the beach marks, the crack origin was identified on the convex surface, and it was located approximately along the midchord of the blade (Fig. 3). After initiation, the crack had propagated progressively over about $85 \%$ of the blade cross section before giving way to final fast fracture. There were no mechanical stress raisers at the crack origin (Figs. 3 and 4). The superficial scratch marks seen on the blade surface near the crack origin (Fig. 4b) were found to be secondary in nature, and they had no role to play in the crack initiation. These scratch marks were caused during the removal of the fractured blade from the compressor disc.
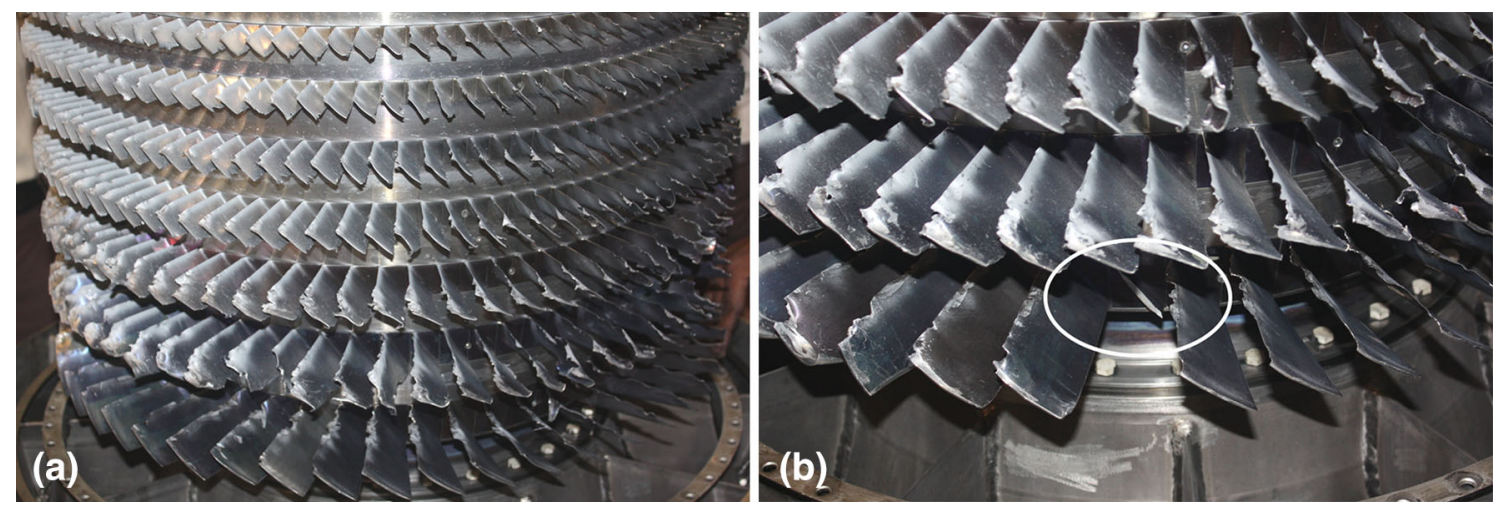

Fig. 1 (a) Damages to the blades in the compressor section of the aeroengine and (b) fracturing of a 1st stage HPCR blade from the root region
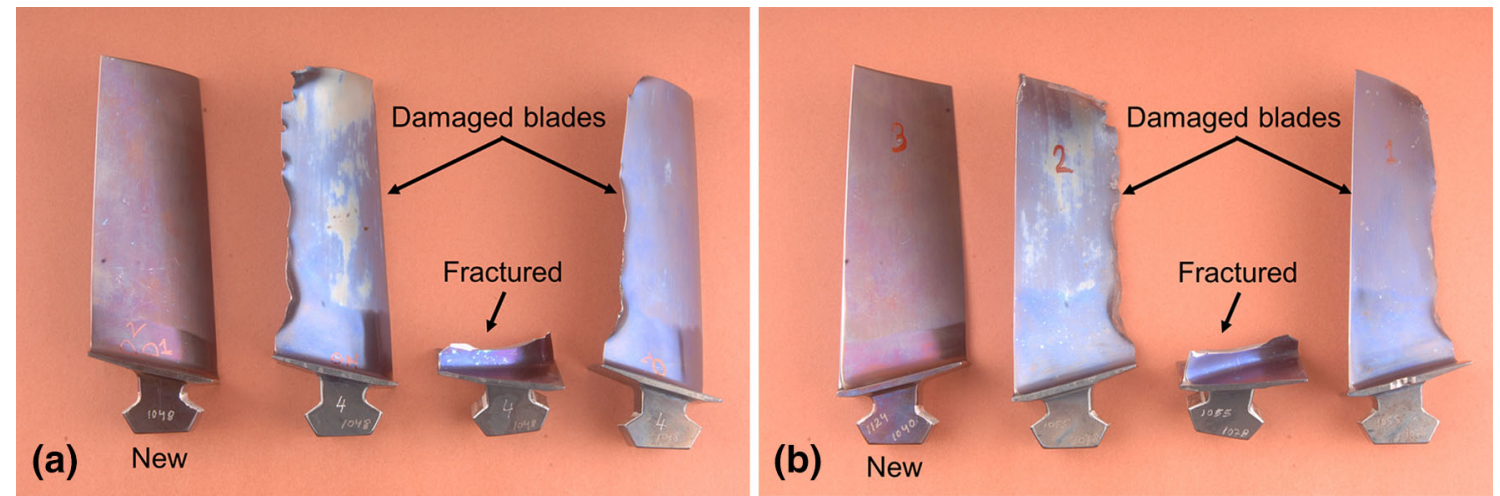

Fig. 2 HPCR blades received for laboratory investigation: (a) convex surface and (b) concave surface 


\section{Scanning Electron Microscopy}

The fractograph in the progressive crack propagation zone showed presence of striations confirming fatigue mode of crack propagation (Fig. 5a). Outside this zone and in the final fracture region, the fracture surface consisted of dimples, typical of fast crack propagation under overload (Fig. 5b). Examination of the crack origin region at higher magnifications confirmed that the fatigue crack initiation was not associated with any mechanical or metallurgical abnormalities (Fig. 6).

The airfoil surfaces of the fractured blade were examined. The surface finish in general was found to be satisfactory. Examination, however, revealed a few shallow, tight cracks on the convex surface and in the vicinity

Table 1 Chemical composition of fractured HPCR blade material

\begin{tabular}{lcc}
\hline \multicolumn{2}{l}{ Composition, wt.\% } \\
\hline Element & BT-6 specification & Fractured HPCR blade \\
\hline $\mathrm{Al}$ & $5.5-7.0$ & 5.8 \\
$\mathrm{~V}$ & $4.0-5.0$ & 4.8 \\
$\mathrm{Fe}$ & $0.3 \max$ & 0.2 \\
$\mathrm{O}$ & 0.15 max & 0.1 \\
$\mathrm{Ti}$ & Balance & Balance \\
\hline
\end{tabular}
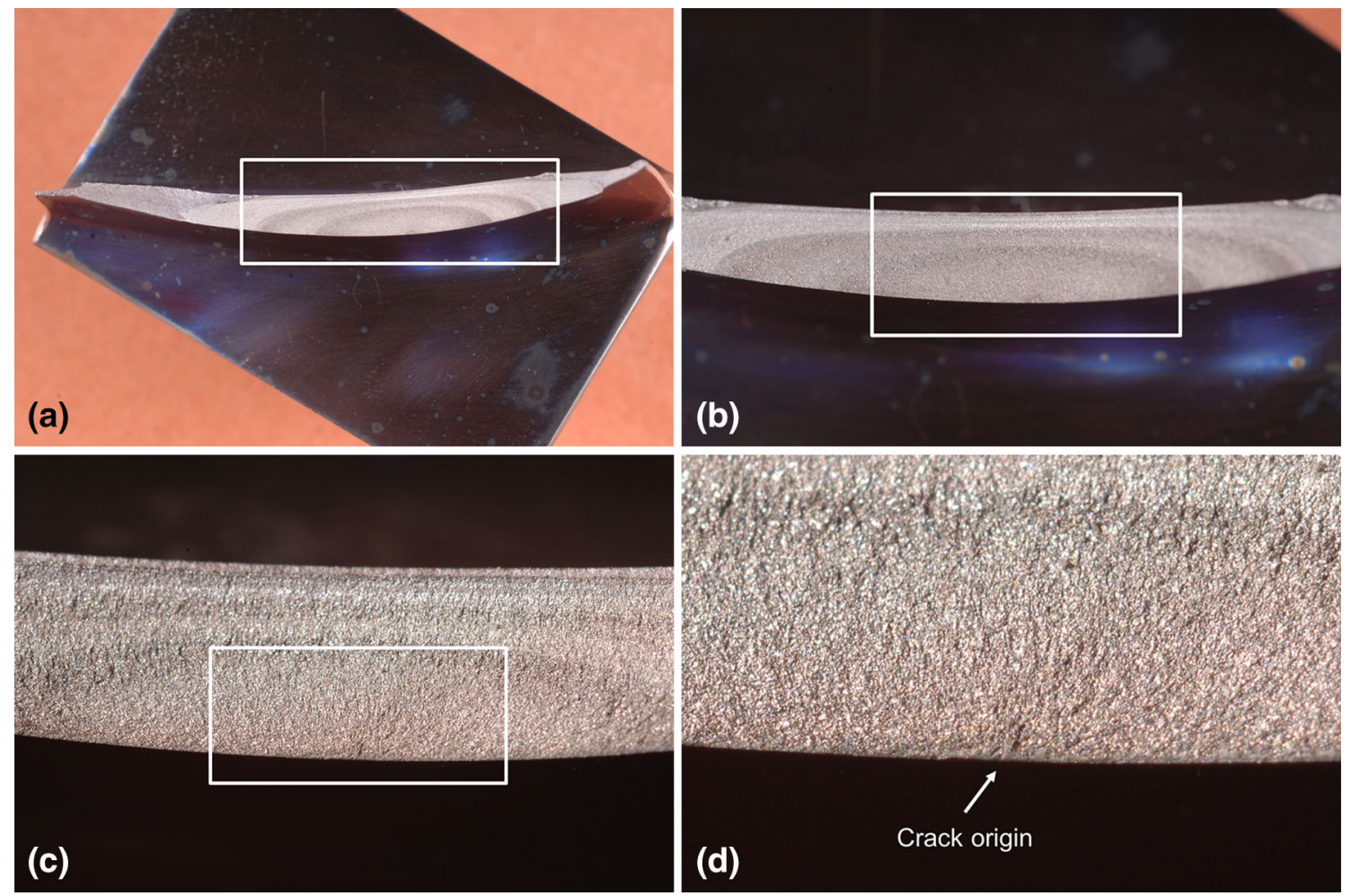

Fig. 3 (a) Semi-elliptical crack arrest marks on the fracture surface, (b) close-up view of the region marked in (a), (c) crack origin region, and (d) magnified view of the region marked in (c) showing absence of any mechanical stress raisers of the fatigue crack origin, $2-3 \mathrm{~mm}$ from the fracture. One such crack is shown in Fig. 7. It is important to note that no such cracks were observed on the airfoil surface of the other two damaged blades, which were located in the engine on either side of the fractured blade.

\section{Material of Construction}

The composition of the blade material conformed to BT- 6 Ti-alloy specification (Table 1). The blade was sectioned longitudinally through the fatigue crack origin, metallographically prepared and examined for microstructure. The microstructures at the fatigue crack origin and in the bulk of the blade are shown in Fig. 8. The microstructures consisted of primary $\alpha$-particles in a matrix of transformed $\beta$. Examination did not reveal any metallurgical abnormalities at the fatigue crack origin. The hardness was measured to be in the range 330-340 HV.

\section{Analysis of Failure}

Fractography study confirmed that the failure of the HPCR blade was by fatigue mechanism. It was established through metallurgical studies that fatigue crack initiation was not due to any stress concentration effects arising from localized mechanical or metallurgical abnormalities. Also, 

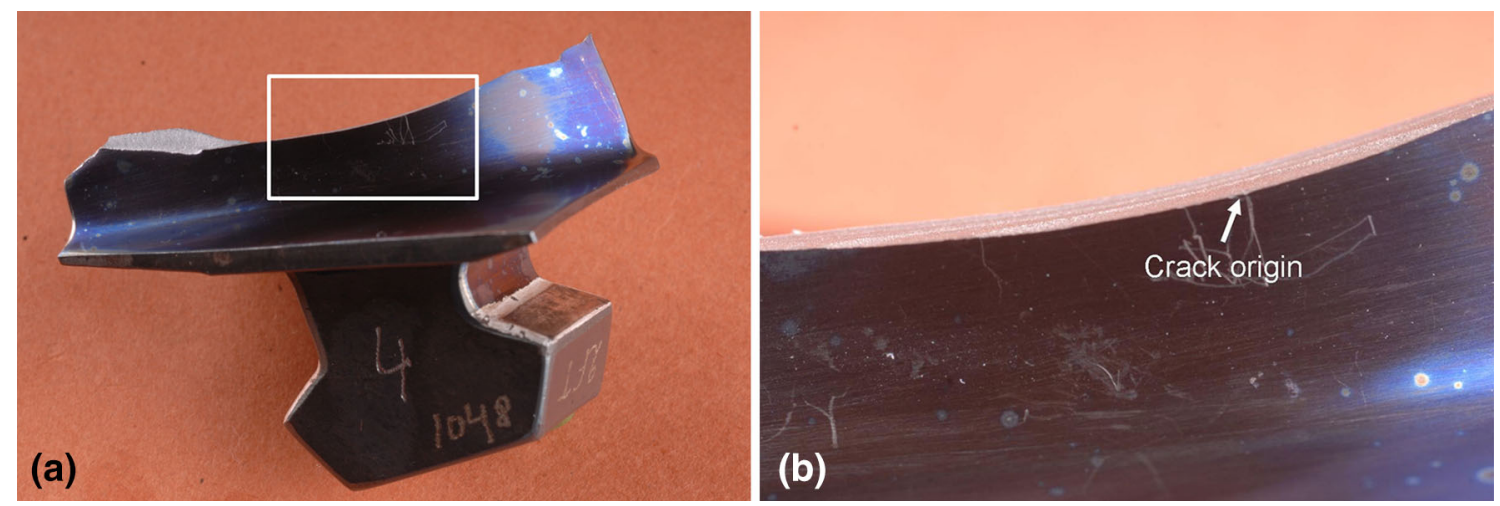

Fig. 4 (a) Crack origin on the convex surface and (b) close-up view showing absence of any mechanical stress raisers
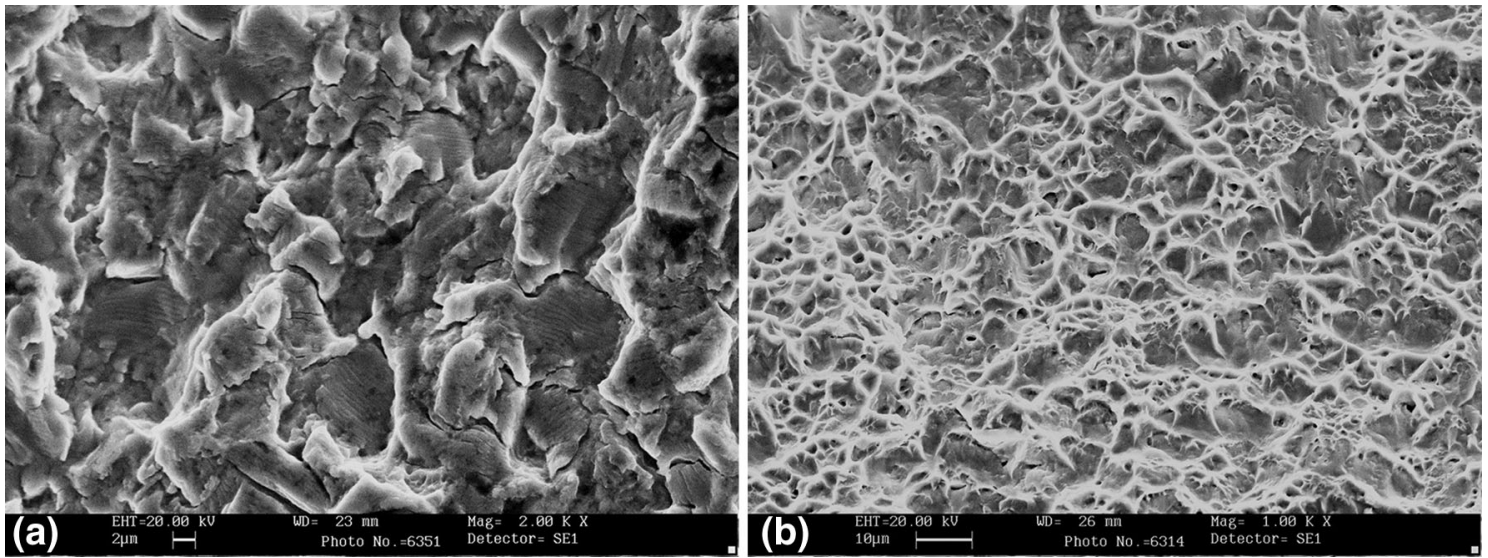

Fig. 5 Scanning electron fractographs of the HPCR blade: (a) fatigue striations in the progressive crack propagation zone and (b) dimple rupture in the final fracture zone
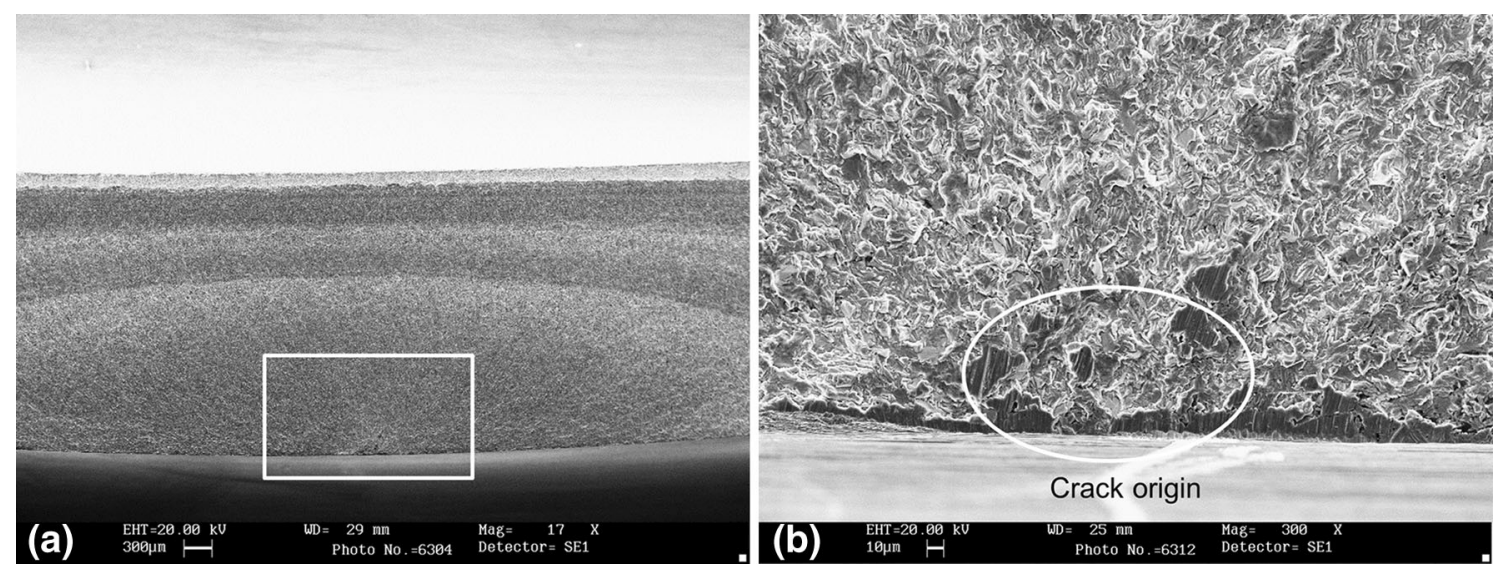

Fig. 6 Scanning electron fractographs: (a) fatigue crack origin region and (b) magnified view of the region marked in (a) showing no metallurgical abnormalities at the fatigue crack origin

no deficiency in the material of construction was responsible for the premature fatigue failure of the blade.

The fracture in the HPCR blade was developed in a plane normal to the blade axis. The major part of the fracture surface had smooth appearance, and it contained several clearly delineated beach marks, having semi-elliptical shape starting from the convex surface. Only about $15 \%$ of the surface was created by fast fracture. Absence of any ridges or stretch zone marks between the beach marks implies that the fatigue failure of the blade was under 

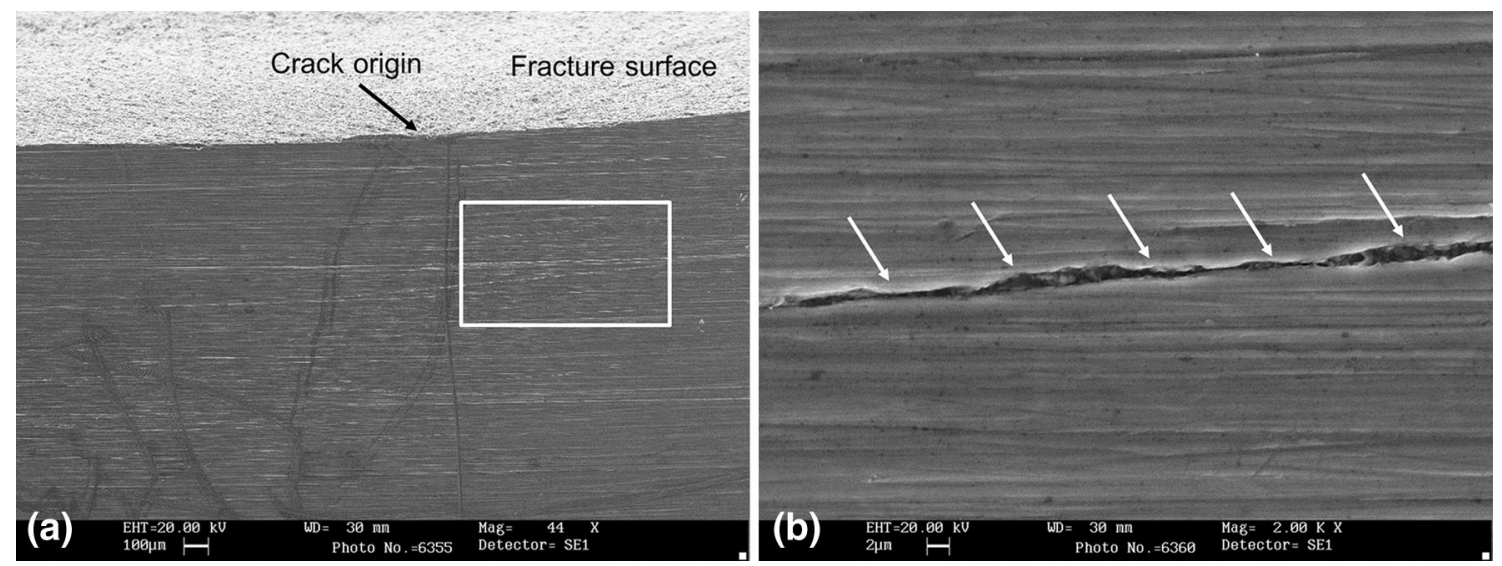

Fig. 7 Secondary electron images showing (a) a shallow, tight crack on the convex surface of the blade at the vicinity of the fatigue crack origin and (b) magnified view of the crack
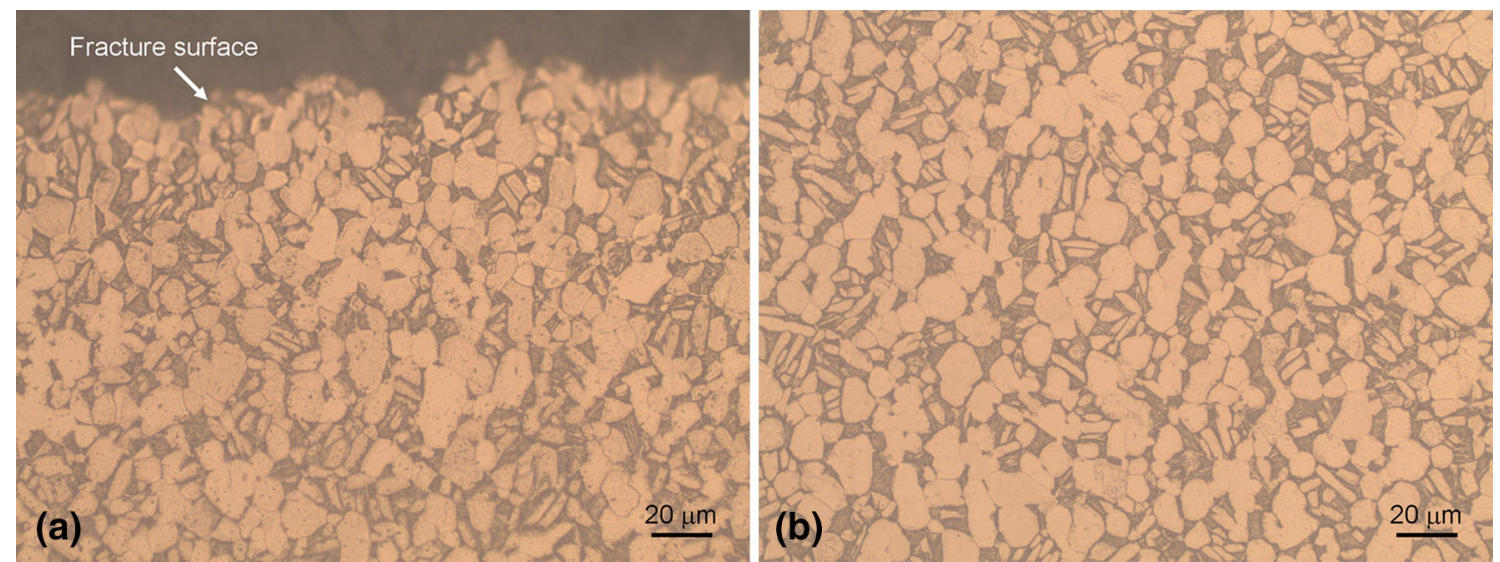

Fig. 8 Optical microstructures on the longitudinal section of the fractured HPCR blade showing primary $\alpha$-particles in a matrix of transformed $\beta$ : (a) at the fatigue crack origin and (b) in the bulk of the blade

relatively low stress levels. Further, the symmetry of beach marks with reference to the blade axis indicates that once initiated, the fatigue crack had propagated mainly under the symmetrical loading with respect to the blade axis.

The location of the crack origin and the characteristic features on the fracture surface indicated that the initial fatigue cracking of the blade had resulted from high amplitude cyclic bending stresses. There was no evidence that any other factors had contributed to the failure. But, the conclusion drawn from this study could not be adequately supported because of the following reasons.

(a) None of the remaining HPCR blades showed any evidences which could be suggestive of high amplitude vibration in the engine.

(b) Since the newly built engine was being run in the test bed as a mandatory requirement prior to fitting onto the aircraft, all important engine parameters were recorded, and they were closely monitored.
Study of the records showed that the engine was healthy, and the vibration level was significantly lower than the allowable maximum limit till the failure of the HPCR blade occurred.

The failure, therefore, appeared to be blade specific, and it was not due to any abnormality in the engine behavior. However, in the absence of any deficiency in the material of construction and local defects, the failure of the blade within $12.2 \mathrm{~h}$ of engine run against a total technical life of $1500 \mathrm{~h}$ could not be explained.

\section{Conclusion Based on Laboratory Investigation}

Despite thorough metallurgical investigation, the primary cause of premature fatigue failure of the HPCR blade could not be established. However, as a preventive measure, it was decided that all blades from this batch of production be rejected. 

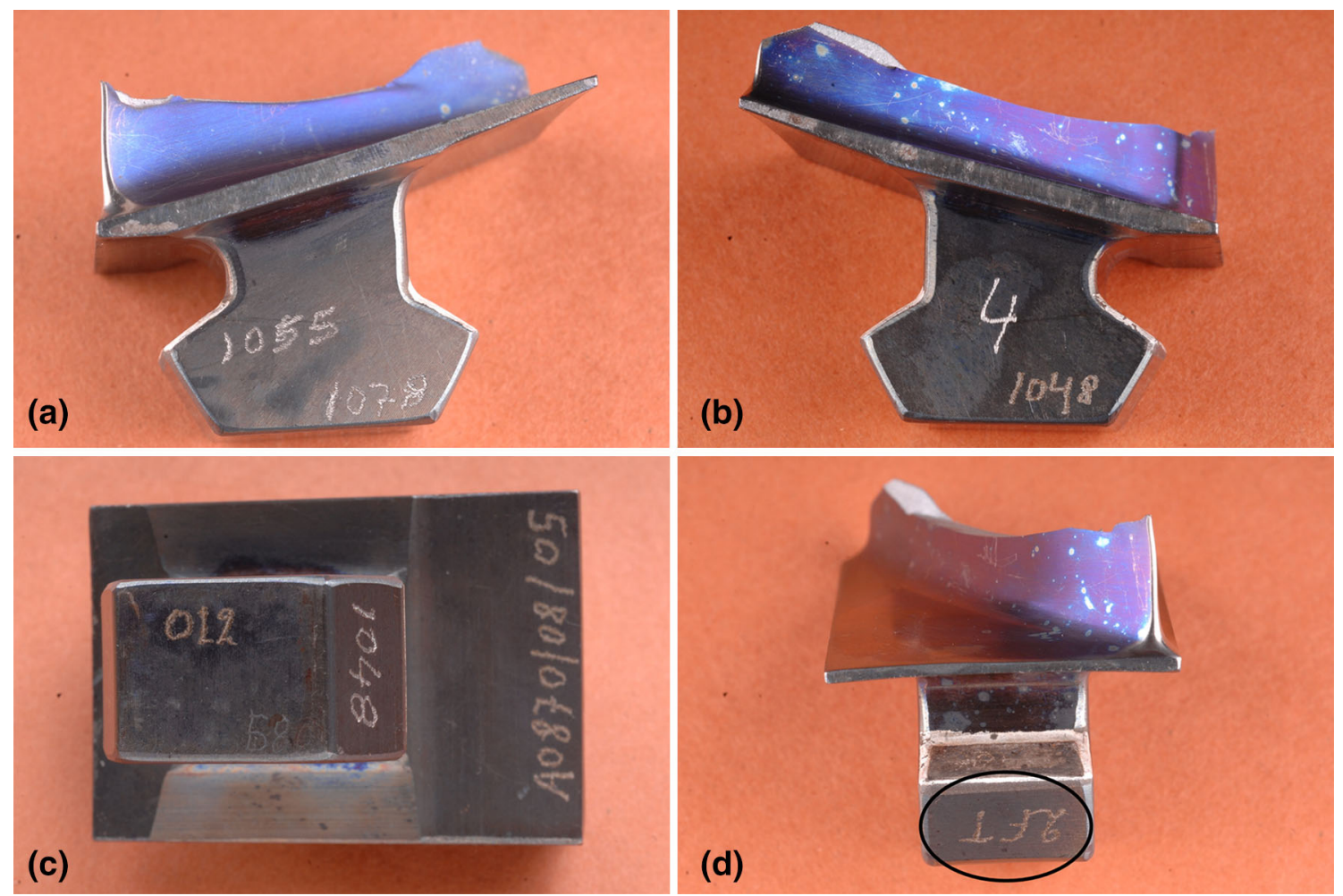

Fig. 9 (a-c) various manufacturing-related identification numbers on the root of the blade and (d) additional identification, marked as "2FT"

\section{Accidental Discovery}

In the final stage of consolidation of the findings of the investigation, the investigators needed the details of the fractured blade for identification of the batch of production. Typically, a blade is identified with the melt number, the forging batch number, the blade production batch number, the individual blade serial number, and the heat treatment batch number. In addition, during assembly of the engine, the location of the blade on the disk in respect of a reference point is also identified. While examining the fractured blade for these details, it was discovered that in addition to the identifications mentioned above, "2FT" was embossed on one of the root faces (Fig. 9). Examination revealed that this was unique to the fractured blade, and no other HPCR blades from the engine had such identification. This raised suspicion, and hence clarification was sought from the manufacturer.

On enquiry, the manufacturer informed that the identification " $2 \mathrm{FT}$ " stood for blade- 2 of the six blades that were identified from a production batch for qualification through "fatigue test." After selection of six blades by random sampling, they were sent to the laboratory for qualification test, and during this time, each blade was identified by a test sample number followed by "FT."

Fatigue testing of the blades was performed on a vibration shaker. This testing consisted of mounting the base of the blade to a vibration plate and tuning in the frequency as well as the amplitude to prescribed levels. The entire test was then monitored based on the blade tip displacement. As per the technology requirement, the blade life specified for qualification was $2 \times 10^{6}$ cycles. Once the blades survived the specified number of cycles, the tests were terminated. Procedure demanded that the tested blades were properly tagged and kept in the inventory for a certain period of time before they could be destroyed.

Investigation revealed that the fractured blade of the engine was one of the fatigue tested blades that were sent to the laboratory for qualification of a particular batch of production. Hence, the blade had already accumulated fatigue damage during the laboratory test and prior to the fitment in the engine. The primary cause of the failure of the blade within $11.2 \mathrm{~h}$ of engine run was thus established. In the normal course of metallurgical investigation, the investigators could never have been able to find that a previously "fatigue tested" blade would find its way into the engine fitments. What caused this failure? The onus was on the manufacturer to investigate further and establish the root cause.

\section{Summary}

The physical cause of a failure, namely stress corrosion cracking or fatigue or hydrogen embrittlement, can be established through metallurgical investigation. But, it may not be sufficient enough for establishing the true cause of failure. It is 
widespread that too much attention is paid to the physical aspect of failure, and in the process, important information available on the failed component goes unnoticed or remains unread. Often, the true cause of failure is not established due to overlooking of minor details and not because of lack of advanced knowledge. As shown in this article, if these details are read, analyzed, and linked appropriately, the outcome of the investigation can be revealing, sometimes, astonishing.

Acknowledgment The assistance provided by Mr. M. Madan during investigation of the failure reported is acknowledged.

\section{References}

1. V. Ramachandran, A.C. Raghuram, R.V. Krishnan, S.K. Bhaumik, Failure Analysis of Engineering Structures: Methodology and Case Histories (ASM International, American Society for Metals, Materials Park, 2005)

2. G.F. Vander Voort, Conducting the failure examination. Pract. Fail. Anal. 1, 14-46 (2001)

3. S.K. Bhaumik, An aircraft accident investigation: revisited. J. Fail. Anal. Prev. 8, 399-405 (2008)

4. P. Daniel, Dennies: How to Organize and Run a Failure Investigation (ASM International, American Society for Metals, Materials Park, 2005) 